\title{
Characterisation of the biological activity of xenin-25 degradation fragment peptides
}

\author{
Christine M A Martin, Vadivel Parthsarathy, Varun Pathak, Victor A Gault, \\ Peter R Flatt and Nigel Irwin
}

SAAD Centre for Pharmacy and Diabetes, University of Ulster, Coleraine, Northern Ireland, BT52 1SA, UK
Correspondence should be addressed to $\mathrm{N}$ Irwin

Email

n.irwin@ulster.ac.uk

\begin{abstract}
Xenin-25, a peptide co-secreted with the incretin hormone glucose-dependent insulinotropic polypeptide (GIP), possesses promising therapeutic actions for obesity-diabetes. However, native xenin-25 is rapidly degraded by serum enzymes to yield the truncated metabolites: xenin 9-25, xenin 11-25, xenin 14-25 and xenin 18-25. This study has examined the biological activities of these fragment peptides. In vitro studies using BRIN-BD11 cells demonstrated that native xenin-25 and xenin 18-25 possessed significant $(P<0.05$ to $P<0.001$ ) insulin-releasing actions at 5.6 and $16.7 \mathrm{mM}$ glucose, respectively, but not at $1.1 \mathrm{mM}$ glucose. In addition, xenin 18-25 significantly $(P<0.05)$ potentiated the insulin-releasing action of the stable GIP mimetic (D-Ala ${ }^{2}$ ) GIP. In contrast, xenin 9-25, xenin 11-25 and xenin 14-25 displayed neither insulinotropic nor GIP-potentiating actions. Moreover, xenin 9-25, xenin 11-25 and xenin 14-25 significantly $(P<0.05$ to $P<0.001)$ inhibited xenin-25 (10 $\left.10^{-6} \mathrm{M}\right)$-induced insulin release in vitro. I.p. administration of xenin-based peptides in combination with glucose to high fat-fed mice did not significantly affect the glycaemic excursion or glucose-induced insulin release compared with controls. However, when combined with (D-Ala $\left.{ }^{2}\right)$ GIP, all xenin peptides significantly $(P<0.01$ to $P<0.001$ ) reduced the overall glycaemic excursion, albeit to a similar extent as (D-Ala ${ }^{2}$ GIP alone. Xenin-25 and xenin 18-25 also imparted a potential synergistic effect on (D-Ala ${ }^{2}$ ) GIP-induced insulin release in high fat-fed mice. All xenin-based peptides lacked significant satiety effects in normal mice. These data demonstrate that the C-terminally derived fragment peptide of xenin-25, xenin 18-25, exhibits significant biological actions that could have therapeutic utility for obesity-diabetes.
\end{abstract}

\section{Key Words}

- glucose-dependent insulinotropic polypeptide (GIP)

- high fat-fed mice

- bioactivity

- xenin-25
Journal of Endocrinology (2014) 221, 193-200

\section{Introduction}

Xenin-25 is a 25 amino acid gastrointestinal hormone secreted from the same enteroendocrine K-cells from which the incretin hormone glucose-dependent insulinotropic polypeptide (GIP) is secreted (Anlauf et al. 2000). Key advances in the understanding of xenin-25 physiology have demonstrated that xenin-25 not only affects gut motility and feeding behaviour (Cline et al. 2007, Leckstrom et al. 2009) but also acts as an independent insulinotropic agent (Taylor et al. 2010) and a potentiator of GIP-induced insulin secretion (Wice et al. 2010, Martin et al. 2012). However, there is still a dearth of information regarding the biological profile of

Published by Bioscientifica Ltd. 
xenin-25, despite its amino acid sequence being highly conserved through evolution (Hamscher et al. 1996). Notwithstanding this, the various biological actions of xenin-25 established to date have aroused significant interest in the possible therapeutic action of stable, enzyme-resistant, xenin-based analogues for the therapy of obesity-diabetes (Martin et al. 2012). This is particularly applicable given that xenin-25 could restore the welldocumented compromised insulin-releasing action of GIP in type 2 diabetes (Nauck et al. 1993).

Similar to most regulatory peptides, native xenin-25 is efficiently degraded by plasma enzymes once secreted into the bloodstream (Taylor et al. 2010, Martin et al. 2012). Recently, the degradation products and enzymatic cleavage sites for native xenin-25 have been determined through the use of electrospray ionisation tandem mass spectrometry (ESI-MS/MS) sequencing, algorithms and databases (Martin etal. 2012). Thus, the plasma enzymatic degradation fragment peptides of native xenin-25 include xenin 9-25, xenin 11-25, xenin 14-25 and xenin 18-25 (Martin et al. 2012). However, the physiological importance of these degradation fragments is largely unknown, and it is conceivable that they could possess important biological functions. In this regard, xenin 18-25 (also named xenin-8) was originally identified in dogs (Feurle et al. 1997) and demonstrated to have insulinotropic effects in the perfused rat pancreas (Silvestre et al. 2003). Despite this, a novel, fully enzymatic resistant form of native xenin-25 was shown to have significantly improved biological activity compared with the native peptide, including enhanced insulin-releasing actions (Martin et al. 2012).

Since therapeutic applications may be found for xenin25 in the future, it is essential to determine the biological significance of the degradation fragment peptides. In light of this, the present study has attempted to elucidate the bioactive domain(s) within the xenin- 25 molecule. Accordingly, we have examined the in vitro effects of xenin 9-25, xenin 11-25, xenin 14-25 and xenin 18-25 on insulin secretion, both alone and in the presence of stimulatory GIP and xenin-25. In addition, the effects of xenin fragment peptides on food intake, anti-hyperglycaemic and insulinotropic activity in vivo were also evaluated.

\section{Materials and methods}

\section{Peptides synthesis}

All peptides were obtained from GL Biochem (Shanghai, China) and characterised using matrix-assisted laser desorption ionisation time-of-flight mass spectrometry, as described previously (Martin et al. 2012). The experimentally derived masses of xenin 9-25, xenin 11-25, xenin 14-25 and xenin 18-25 were 1991.3, $1833.3,1450.4$ and 1045.8 Da, respectively, which corresponded closely to the theoretical masses of 1992.4, 1834.3, 1450.3 and 1046.3 Da respectively.

\section{In vitro insulin secretion}

BRIN-BD11 cells were harvested with the aid of trypsin/EDTA (Gibco), seeded into 24-multiwell plates (Nunc, Roskilde, Denmark) at a density of $1.0 \times 10^{5}$ cells/well, and allowed to attach overnight at $37^{\circ} \mathrm{C}$. Acute tests for insulin release were preceded by $40 \mathrm{~min}$ preincubation at $37^{\circ} \mathrm{C}$ in $1.0 \mathrm{ml}$ Krebs-Ringer bicarbonate buffer $(115 \mathrm{mM} \mathrm{NaCl}$, $4.7 \mathrm{mM} \mathrm{KCl}, 1.28 \mathrm{mM} \mathrm{NaCl}_{2}, 1.2 \mathrm{mM} \mathrm{KH}_{2} \mathrm{PO}_{4}, 1.2 \mathrm{mM}$ $\mathrm{MgSO}_{4}, 10 \mathrm{mM} \mathrm{NaHCO}, 0.5 \%$ (w/v) BSA, pH 7.4) supplemented with $1.1 \mathrm{mM}$ glucose. Test incubations were performed $(n=8)$ in the presence of $1.1,5.6$ or $16.7 \mathrm{mM}$ glucose, as appropriate, over a range of concentrations $\left(10^{-12}\right.$ to $\left.10^{-6} \mathrm{M}\right)$ of xenin fragment peptides in the presence or absence of $10^{-7} \mathrm{M}\left(\mathrm{D}-\mathrm{Ala}^{2}\right) \mathrm{GIP}$ or $10^{-6} \mathrm{M}$ xenin-25. After $20 \mathrm{~min}$ incubation, the buffer was removed and used for the measurements of insulin by RIA (Flatt \& Bailey 1981).

\section{Animals}

Male NIH Swiss mice (Harlan, Blackthorn, Oxfordshire, UK) had free access to drinking water and standard rodent maintenance $(10 \%$ fat, $30 \%$ protein and $60 \%$ carbohydrate, Trouw Nutrition, Cheshire, UK) or high fat (45\% fat, $35 \%$ carbohydrate and $20 \%$ protein, Special Diet Services, Witham, Essex, UK) diet as appropriate. Before commencement of glucose homoeostasis and insulin secretory studies, high fat-fed mice were maintained on high-fat diet from 6 weeks of age for 140 days. Obesity, hyperglycaemia and insulin resistance were clearly manifested, as judged by body weight, plasma glucose and insulin analyses. All experiments were carried out in accordance with the UK Animals (Scientific Procedures) Act 1986. The animals were housed individually in an air-conditioned room at $22 \pm 2{ }^{\circ} \mathrm{C}$ with a $12 \mathrm{~h}$ light: $12 \mathrm{~h}$ darkness cycle (lights off between 0930 to $2130 \mathrm{~h}$ ).

\section{Glucose-lowering and insulinotropic activity in vivo}

The glucose homoeostatic and insulin secretory effects of xenin- 25 and related fragment peptides $(25 \mathrm{nmol} / \mathrm{kg}$ body weight; i.p. injection), both alone and in the presence of

Published by Bioscientifica Ltd 
A

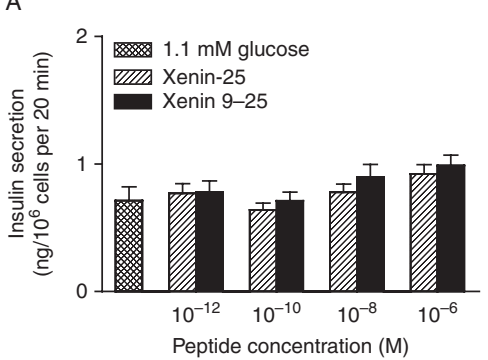

D

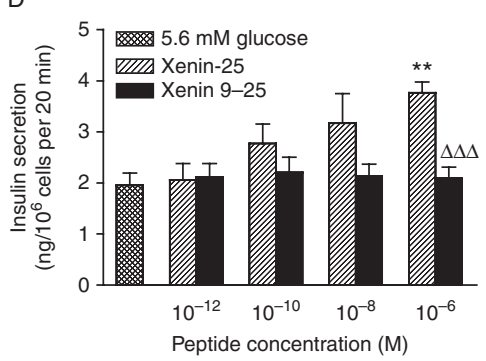

G

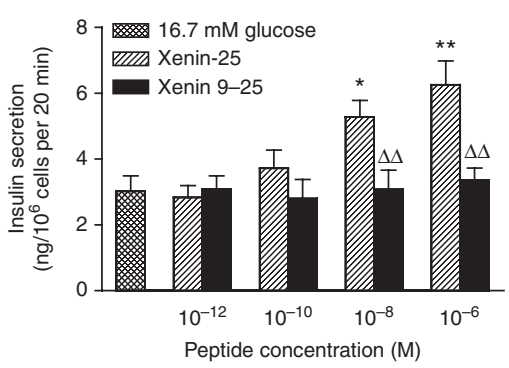

B

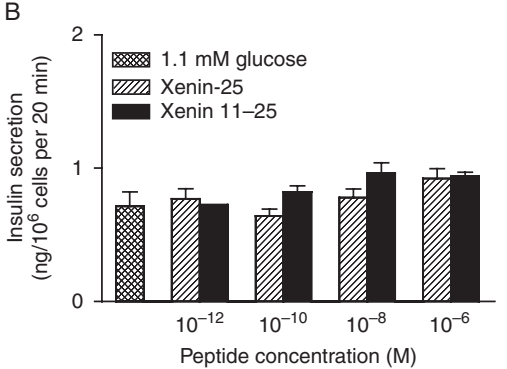

E

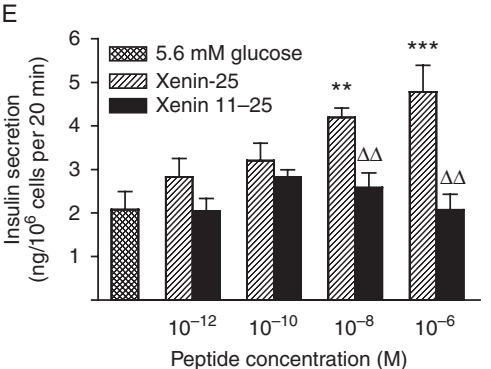

$\mathrm{H}$

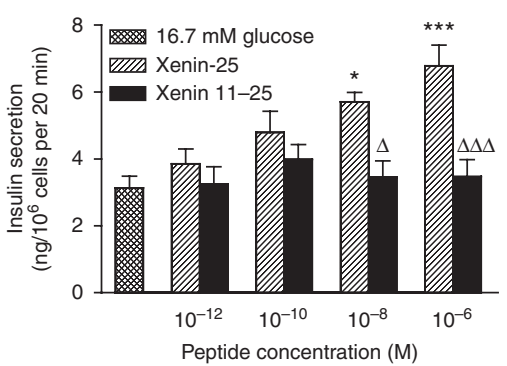

C

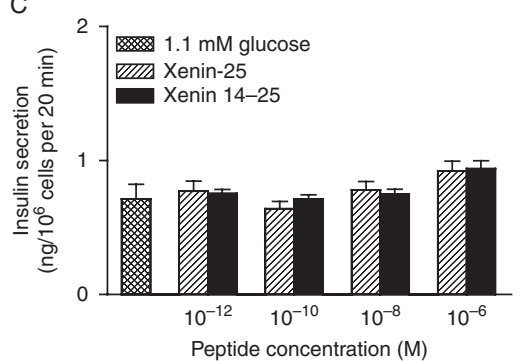

$\mathrm{F}$
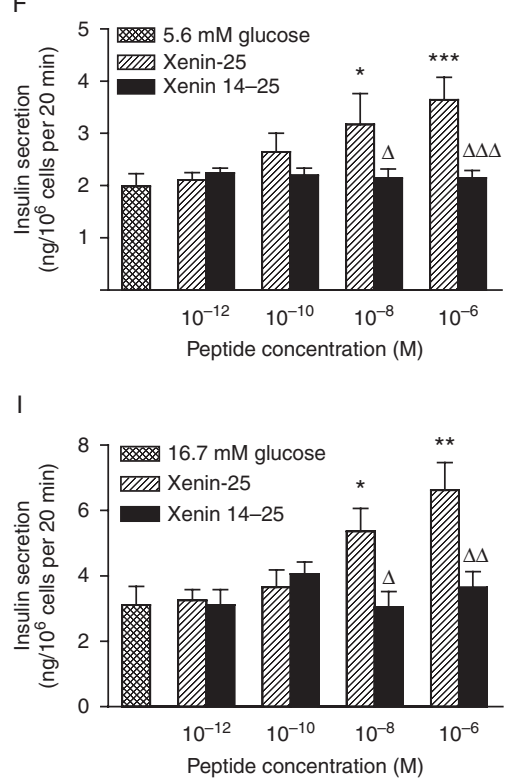

Figure 1

Insulinotropic effects of xenin-25, xenin 9-25, xenin 11-25 and xenin 14-25 in BRIN-BD11 cells. Cells were exposed to various concentrations of xenin peptides for an acute 20 min period in the presence of (A, B and C) 1.1, (D, E and F) 5.6 or (G, H and I) $16.7 \mathrm{mM}$ glucose. Values represent

(D-Ala $\left.{ }^{2}\right)$ GIP ( $25 \mathrm{nmol} / \mathrm{kg}$ body weight; i.p. injection), were examined in combination with i.p. glucose injection (18 $\mathrm{mmol} / \mathrm{kg}$ body weight) in non-fasted high fat-fed mice. These doses were chosen based on our extensive experience with xenin and GIP peptides in this animal model (Gault et al. 2002, Taylor et al. 2010, Porter et al. 2011, Irwin et al. 2012, Martin et al. 2012). The high fat-fed mouse model was selected in order to establish whether the xenin-related peptides could enhance GIP-mediated effects in a type 2 diabetic model known to have compromised GIP action (Martin et al. 2012). Blood samples, collected from the cut tip of the tail vein of conscious mice at the times indicated in the figures, were immediately centrifuged using a Beckman microcentrifuge (Beckman Instruments, High Wycombe, UK) for $30 \mathrm{~s}$ at $13000 \mathrm{~g}$. The resulting plasma was then aliquoted into fresh Eppendorf tubes and stored at $-20^{\circ} \mathrm{C}$ until analyses for glucose and insulin. mean \pm S.E.M. for eight separate observations. ${ }^{*} P<0.05, * * P<0.01$, $\star * \star P<0.001$ compared with respective glucose control. ${ }^{\Delta} P<0.05,{ }^{\Delta \Delta} P<0.01$ and ${ }^{\Delta \Delta \Delta} P<0.001$ compared with native xenin-25 at the same concentration.

\section{Effects on food intake in vivo}

For food intake experiments, lean NIH mice were fasted for $12 \mathrm{~h}$ before i.p. injection of $(500 \mathrm{nmol} / \mathrm{kg})$ of native xenin25 or related analogues. This dose was chosen based on previous food intake dose-response studies with xenin-25, where $500 \mathrm{nmol} / \mathrm{kg}$ was the lowest effective dose when administered i.p. (Taylor et al. 2010). Mice were then allowed free access to normal chow. Cumulative food intake was measured at 15, 30, 60, 90 and 120 min post-injection.

\section{Plasma glucose and insulin assays}

Plasma glucose was assayed by an automated glucose oxidase procedure using a Beckman Glucose Analyzer II. Plasma insulin was assayed by a dextran-charcoal RIA as described previously (Martin et al. 2012).

Published by Bioscientifica Ltd 


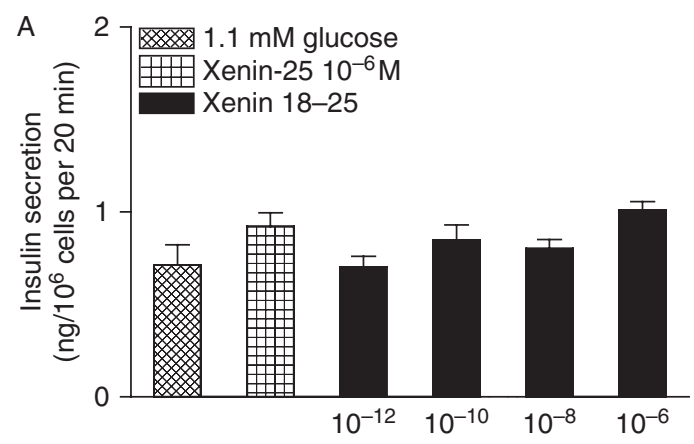

Peptide concentration (M)
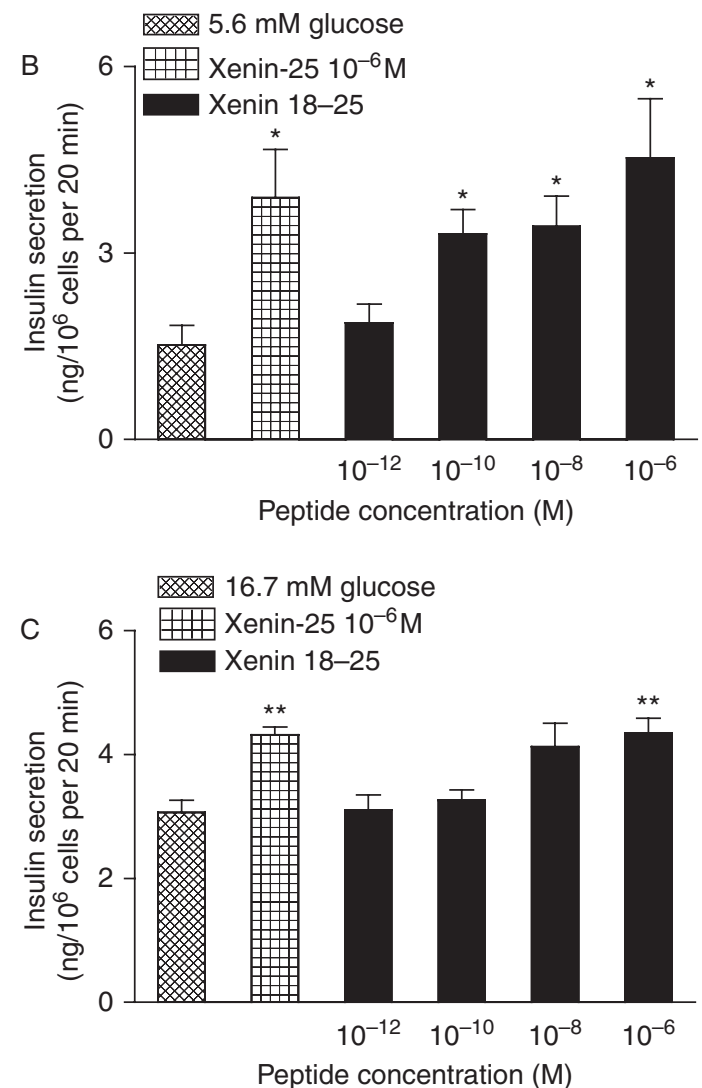

Figure 2

Insulinotropic effects of xenin-25 and xenin 18-25 in BRIN-BD11 cells. Cells were exposed to various concentrations of xenin peptides for an acute 20 min period in the presence of (A) 1.1, (B) 5.6 or (C) $16.7 \mathrm{mM}$ glucose. Values represent mean \pm s.E.M. for eight separate observations. ${ }^{*} P<0.05$ and $* * P<0.01$ compared with respective glucose control.

\section{Statistical analysis}

Results are expressed as mean \pm s.E.M., and data were compared using unpaired Student's $t$-test. Where appropriate, data were compared using one-way ANOVA, followed by the Student-Newman-Keuls post hoc test. Groups of data from both were considered to be significantly different if $P<0.05$.

\section{Results}

\section{Actions of xenin-25 and related fragment peptides on} insulin secretion in clonal BRIN-BD11 cells

Xenin-25 did not induce insulin release at $1.1 \mathrm{mM}$ glucose (Fig. 1A, B and C); however, it enhanced insulin release in a concentration-dependent manner at 5.6 and $16.7 \mathrm{mM}$ glucose levels (Fig. 1D, E, F, G, H and I). In a similar fashion, xenin $18-25$ significantly $(P<0.05$ to $P<0.01)$ augmented insulin secretion at both 5.6 and $16.7 \mathrm{mM}$ glucose concentrations, but not at $1.1 \mathrm{mM}$ glucose (Fig. 2). In contrast, xenin 9-25, xenin 11-25 and xenin 14-25 had no observable insulinotropic actions (Fig. 1A, B, C, D, E, F, G, H and $\mathrm{I}$ ). Of the xenin fragments examined, only xenin 18-25 significantly $(P<0.05)$ augmented $\left(D-\mathrm{Ala}^{2}\right)$ GIP-induced $\left(10^{-7} \mathrm{M}\right)$ insulin secretion (Fig. 3A). When incubated in the presence of native xenin-25, xenin 9-25 and xenin 14-25 significantly $(P<0.05$ to $P<0.001)$ decreased xenin25-generated insulin secretion at the concentrations of $10^{-10} \mathrm{M}$ and above (Fig. 3B). Xenin 11-25 also significantly $(P<0.001)$ reduced xenin-25-stimulated insulin secretion, but only at $10^{-6} \mathrm{M}$ (Fig. 3B). In contrast, when incubated in the presence of xenin-25, xenin $18-25\left(10^{-6} \mathrm{M}\right)$ enhanced $(P<0.05)$ the overall insulin secretory response from BRINBD11 cells when compared with xenin-25 alone (Fig. 3B).

\section{Antihyperglycaemic and insulin-releasing activity of xenin-25 and related fragment peptides in high fat-fed mice}

The relative glucose-lowering and insulinotropic abilities of xenin-25, xenin 9-25, xenin 11-25, xenin 14-25 and xenin 18-25 in high fat-fed mice are shown in Fig. 4. Injection of glucose alone resulted in a rapid and marked increase in individual and overall plasma glucose levels (Fig. 4). Xenin-25 and xenin 18-25 had a tendency to reduce plasma glucose levels and increase plasma insulin concentrations, but this failed to reach significance over the 60 min observation period (Fig. 4). As such, an increased sample size may have improved the statistical power of this experiment. However, all xenin-based peptides significantly $(P<0.01$ to $P<0.001)$ lowered the overall glycaemic excursion in high fat-fed mice when injected concomitantly with (D-Ala ${ }^{2}$ )GIP (Fig. 5A and B), although the magnitude of reduction was similar to administration of (D-Ala ${ }^{2}$ )GIP alone (Fig. 5A and B). This was associated with significantly $(P<0.01$ to $P<0.001)$ increased plasma insulin concentrations $15 \mathrm{~min}$ postinjection in all treatment groups (Fig. 5C). However,

Published by Bioscientifica Ltd. 

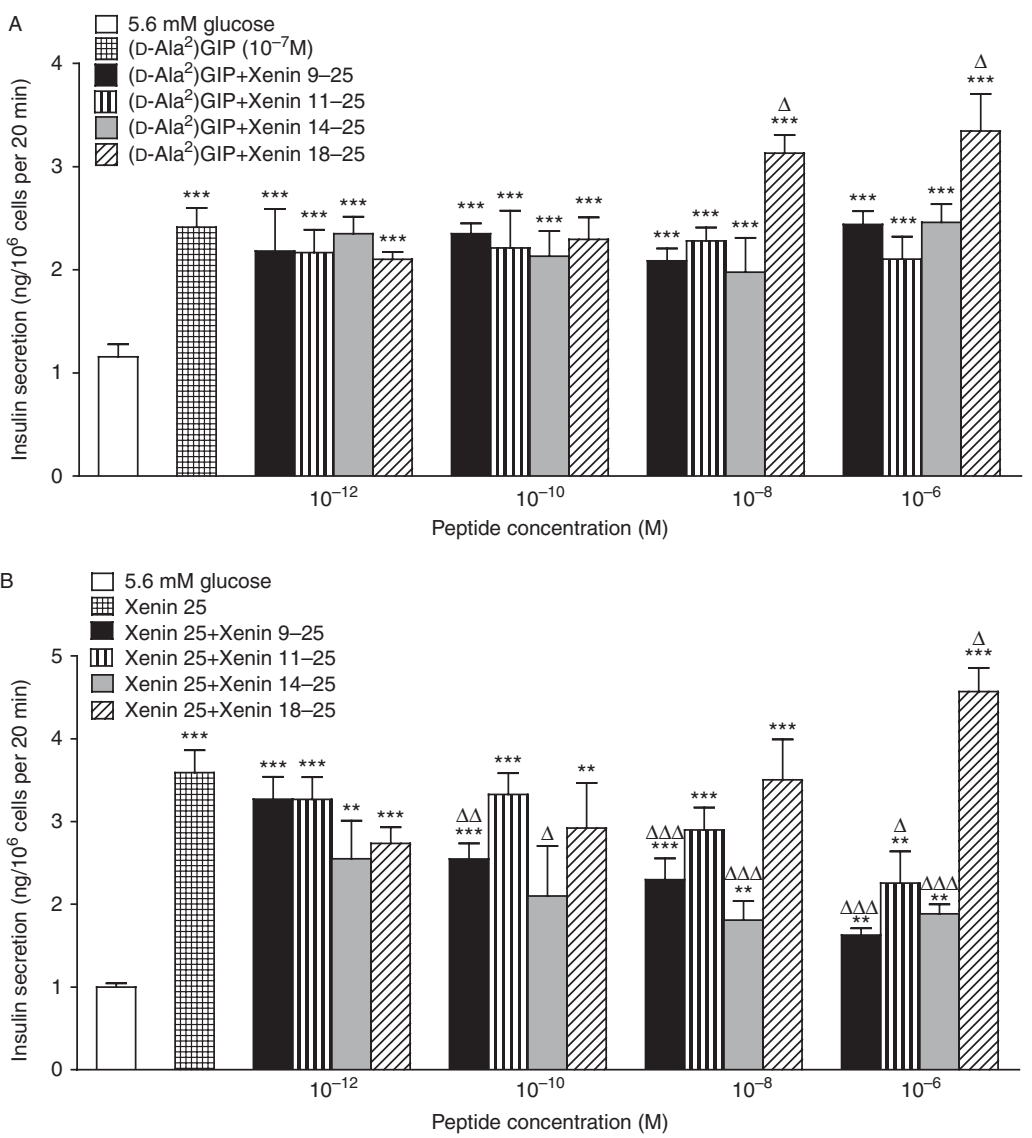

Figure 3

Insulinotropic effects of xenin 9-25, xenin 11-25, xenin 14-25 and xenin 18-25 in the presence of (A) (D-Ala $)$ GIP and (B) xenin-25 in BRIN-BD11 cells. Cells were exposed to various concentrations of xenin peptides in the presence of (A) (D-Ala $)$ GIP $\left(10^{-7} \mathrm{M}\right)$ and (B) xenin-25 $\left(10^{-6} \mathrm{M}\right)$ in BRIN-BD11 cells for an

corresponding 0-60-min overall glucose-induced insulin values were significantly $(P<0.05)$ elevated only in mice treated with xenin-25 or xenin 18-25 in combination with $\left(\right.$ D-Ala ${ }^{2}$ GIP when compared with controls (Fig. 5D).

\section{Satiety effects of xenin-25 and related fragment peptides in normal mice}

None of the peptides examined had any significant effects on feeding behaviour compared with saline-treated controls over the 120 min period (Fig. 6). However, native xenin-25 did have a clear non-significant tendency to reduce food intake at each observation point (Fig. 6).

\section{Discussion}

Xenin-25 is considered as having potential for future treatment of type 2 diabetes based on encouraging acute $20 \mathrm{~min}$ period in the presence of $5.6 \mathrm{mM}$ glucose. Values represent mean \pm S.E.M. for eight separate observations. ${ }^{* * P} P<0.01$ and $* * * P<0.001$ compared with $5.6 \mathrm{mM}$ glucose control. ${ }^{\Delta} P<0.05,{ }^{\Delta \Delta} P<0.01$ and ${ }^{\Delta \Delta \Delta} P<0.001$ compared with $\left(\mathrm{D}-\mathrm{Ala}^{2}\right) \mathrm{GIP}\left(10^{-7} \mathrm{M}\right)$ or xenin- $25\left(10^{-6} \mathrm{M}\right)$ as appropriate.

findings from cellular and animal models (Taylor et al. 2010, Wice et al. 2010, Martin et al. 2012). However, the rapid degradation of xenin-25 by plasma enzymes and consequent short biological half-life (Taylor et al. 2010) is a major factor that hampers possible therapeutic use of the peptide. Accordingly, we have recently shown that an enzyme-resistant fatty acid-derivatised analogue of xenin25 , xenin-25(Lys ${ }^{13} \mathrm{PAL}$ ), has improved biological activity compared with the native peptide (Martin et al. 2012). Despite this, there is a possibility that the recently characterised enzymatic degradation fragments of xenin-25 (Martin et al. 2012) may have a physiological role in relation to the overall biological effects of xenin-25. As such, xenin 18-25 was demonstrated to possess insulin-releasing actions in the perfused rat pancreas (Silvestre et al. 2003).

Consistent with previous observations using clonal pancreatic BRIN-BD11 cells (Taylor et al. 2010,

Published by Bioscientifica Ltd. 

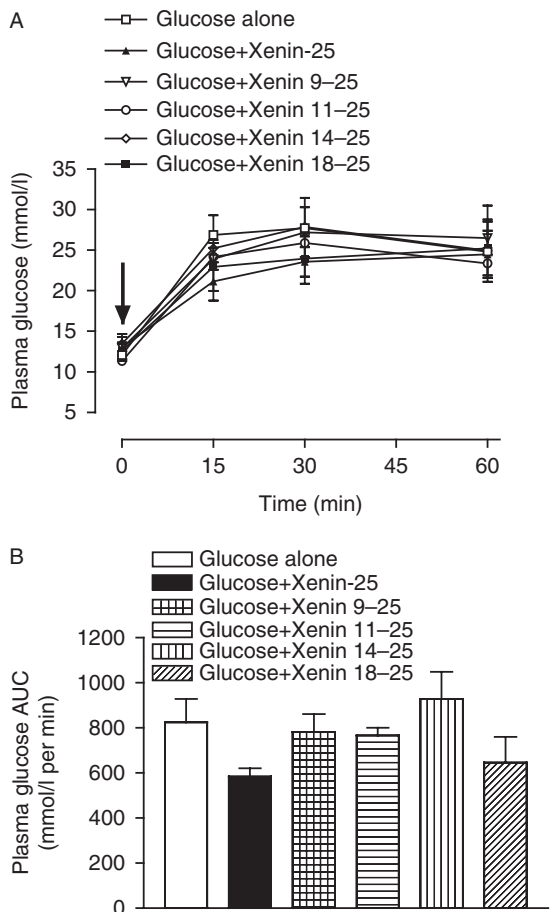

C
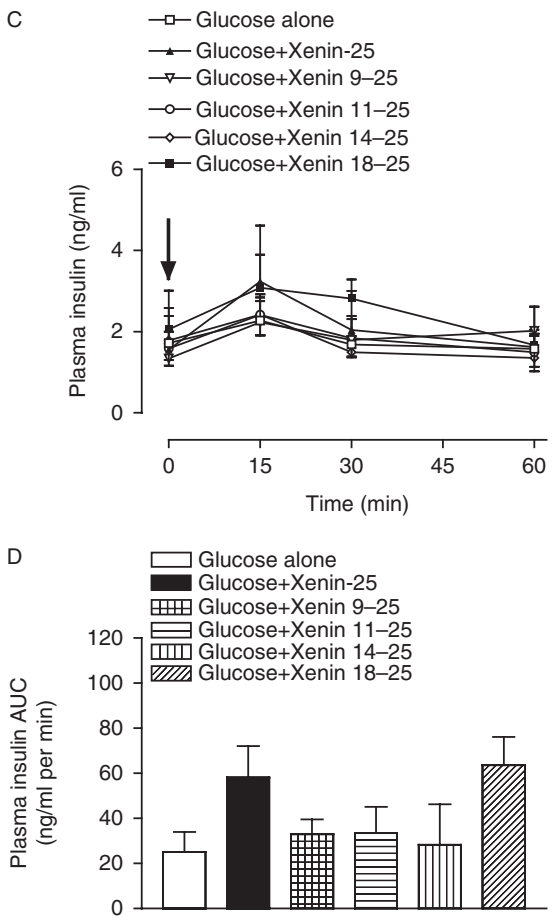

Figure 4

Effects of xenin-25, xenin 9-25, xenin 11-25, xenin $14-25$ and xenin $18-25$ on glucose homeostasis and insulin concentrations in high fat-fed mice. Plasma (A) glucose and (C) insulin concentrations were measured before and after i.p. administration of glucose alone ( $18 \mathrm{mmol} / \mathrm{kg}$ body weight), or in combination with xenin-related peptide (each at $25 \mathrm{nmol} / \mathrm{kg}$ ). The time of injection is indicated by the arrow. Plasma (B) glucose and (D) insulin area under the curve (AUC) values for 0-60 min post injection are also shown. Values represent mean \pm s.E.M. for eight mice.
Martin et al. 2012), xenin-25 induced a concentrationdependent increase in insulin release at physiological and supraphysiological glucose concentrations. Importantly, there was no observable augmentation of insulin release at $1.1 \mathrm{mM}$ glucose levels, indicating a glucose-dependent nature of the insulinotropic actions of xenin-25. In contrast, all xenin-25 fragment peptides, barring xenin 18-25, lacked insulinotropic activity either alone or in the presence of $\left(\mathrm{D}-\mathrm{Ala}^{2}\right) \mathrm{GIP}$, a stable and potent GIP agonist (Porter et al. 2011). In addition, when incubated with stimulatory xenin-25 $\left(10^{-6} \mathrm{M}\right)$, these non-insulinreleasing fragment peptides significantly countered the ability of the native peptide to enhance insulin secretion, albeit at high concentrations. Thus, xenin 9-25, xenin 11-25 and xenin 14-25 might have a role in the regulation of the physiological actions of the parent peptide by interference or inhibition of the insulinotropic effects of xenin-25. Indeed, it has previously been shown that the major degradation fragment of GIP, GIP(3-42), can induce antagonism at the GIP receptor (Gault et al. 2002). However, further in vivo studies are required to elucidate whether the interactions observed in the present study occur at physiologically relevant concentrations.

To evaluate the biological actions of xenin fragment peptides on glucose homeostasis in vivo, we employed high fat-fed mice. This is an extensively studied animal model displaying several abnormal characteristic of type 2 diabetes, including obesity, insulin resistance and moderate hyperglycaemia (Irwin et al. 2012). The present results corroborate the previous findings that xenin-25 displayed notable insulinotropic and glucose lowering activity when administered in conjunction with (D-Ala ${ }^{2}$ GIP to high-fat mice (Martin et al. 2012). Thus, type 2 diabetes is characterised by a reduced response to the biological actions of GIP (Nauck et al. 1993), making high fat-fed mice an excellent model for the current investigations. Moreover, in agreement with the lack of biological activity in vitro, all fragment peptides, besides xenin 18-25, displayed no improved glucose homeostatic or insulinreleasing actions when administered alone or in combination with (D-Ala ${ }^{2}$ GIP in high-fat mice. This lack of in vivo biological action of the fragment peptides was mirrored by studies examining feeding behaviour, as we were unable to demonstrate any satiety effects in normal mice. Consistent with earlier reports (Cline et al. 2007, Cooke et al. 2009, Leckstrom et al. 2009), a mild satiating effect of native xenin-25 was observed in vivo, corroborating use of this model to investigate the biological actions of xenin-25 fragment peptides. Indeed, it has recently been shown that xenin-25 induces appetite-suppressive

Published by Bioscientifica Ltd 

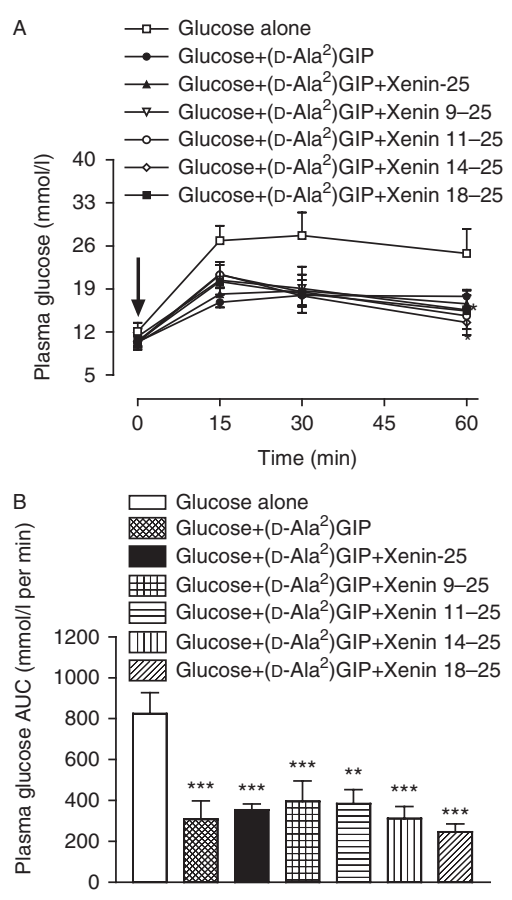

C $\quad \rightarrow-$ Glucose alone

$\rightarrow-$ Glucose+(D-Ala $\left.{ }^{2}\right)$ GIP

× Glucose+(D-Ala ${ }^{2} \mathrm{GIP}+\mathrm{Xenin}-25$

$\rightarrow-$ Glucose $+\left(\mathrm{D}-\mathrm{Ala}^{2}\right) \mathrm{GlP}+\mathrm{Xenin} 9-25$

$\rightarrow-$ Glucose+(D-Ala $\left.{ }^{2}\right) \mathrm{GIP}+\mathrm{Xenin} 11-25$
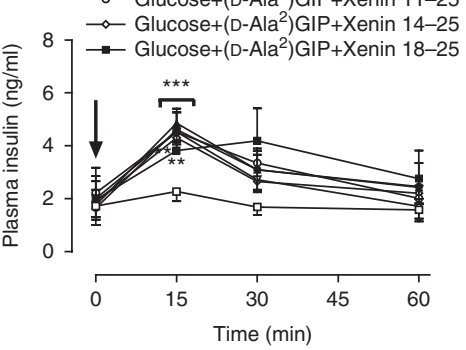

D

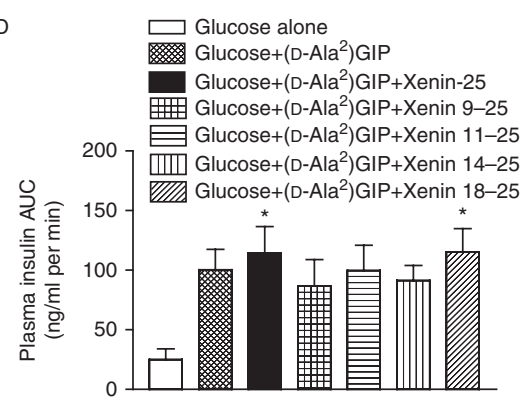

Figure 5

Glucose homoeostatic and insulinotropic effects of xenin-25, xenin 9-25, xenin 11-25, xenin 14-25 and xenin 18-25 in the presence of (D-Ala $\left.{ }^{2}\right)$ GIP in high fat-fed mice. Plasma (A) glucose and (C) insulin concentrations were measured before and after i.p. administration of glucose $(18 \mathrm{mmol} / \mathrm{kg}$ body weight), or together with $\left(\mathrm{D}-\mathrm{Ala}{ }^{2}\right) \mathrm{GIP}(25 \mathrm{nmol} / \mathrm{kg})$ alone and in combination with xenin-related peptide (each at $25 \mathrm{nmol} / \mathrm{kg}$ ). The time of injection is indicated by the arrow. Plasma (B) glucose and (D) insulin area under the curve (AUC) values for 0-60 min post injection are also shown. Values represent mean \pm s.E.M. for eight mice. $* P<0.05, * * P<0.01$ and $* * * P<0.001$ compared with glucose alone. effects through delayed gastric emptying and activation of cells in the nucleus of the solitary tract (Kim \& Mizuno 2010). Moreover, administration of suprapharmacological doses of the xenin peptides, and particularly xenin-25, may have yielded more significant observations on appetite suppression.

The importance of the C-terminus of xenin-25 in terms of biological activity has been indicated previously. As such, xenin 18-25 was shown to have direct effects on pancreatic hormone secretion (Silvestre et al. 2003). We have confirmed these findings in the present study, where xenin 18-25 had equipotent insulinotropic effects to the native peptide. Moreover, xenin 18-25 and xenin-25 displayed synergistic-like effects on the insulin-releasing actions of (D-Ala ${ }^{2}$ )GIP in vivo (Taylor et al. 2010, Martin et al. 2012). Furthermore, when incubated in combination with xenin-25, xenin 18-25 did not perturb the insulinotropic effect of the native peptide, unlike the larger degradation fragment peptides. Indeed, combined incubation of xenin-25 and xenin 18-25 resulted in markedly enhanced insulinotropic actions. These observations of beneficial in vitro effects were confirmed by studies assessing the metabolic effects of xenin 18-25 in high fat-fed mice. Xenin 18-25 did not affect feeding behaviour, which may suggest altered passage of this fragment peptide through the blood-brain barrier (Kim \& Mizuno 2010); however, further studies are required to confirm this.

In conclusion, the present study has characterised the bioactivity of all xenin-25 degradation fragment peptides (Martin et al. 2012). The results show that xenin 9-25, xenin 11-25 and xenin 14-25 exhibit no distinct biological actions, but may act to regulate the activity of

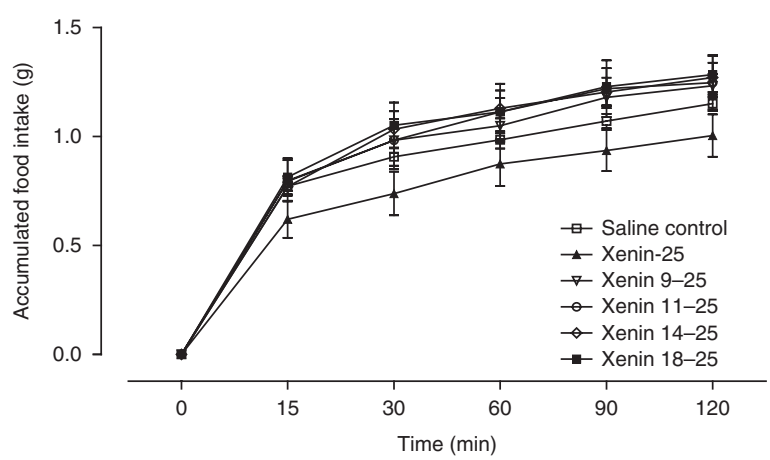

Figure 6

Effects of xenin-25, xenin 9-25, xenin 11-25, xenin 14-25 and xenin 18-25 on cumulative food intake in normal mice. Cumulative food intake was measured after i.p. administration of each peptide $(500 \mathrm{nmol} / \mathrm{kg})$. Values represent mean \pm s.E.M. for eight mice.

Published by Bioscientifica Ltd. 
the parent peptide. Conversely, xenin 18-25 had essentially similar biological actions as native xenin-25, but lacked significant satiety effects. Development of shorter bioactive forms of xenin-25, based on xenin 18-25, could be conceivable in the future, which would reduce production costs and possibly facilitate non-injectable drug delivery.

\section{Declaration of interest}

V A G, P R F and N I hold shares with Diabetica Ltd, which has patents for exploitation of peptide therapeutics.

\section{Funding}

This study was supported in part by a PhD studentship from the Department of Education and Learning, Northern Ireland and the SAAD Trading and Contracting Company.

\section{References}

Anlauf M, Weihe E, Hartschuh W, Hamscher G \& Feurle GE 2000 Localization of xenin-immunoreactive cells in the duodenal mucosa of humans and various mammals. Journal of Histochemistry and Cytochemistry 48 1617-1626. (doi:10.1177/002215540004801205)

Cline MA, Nandar W \& Rogers JO 2007 Xenin reduces feed intake by activating the ventromedial hypothalamus and influences gastrointestinal transit rate in chicks. Behavioural Brain Research 179 28-32. (doi:10.1016/j.bbr.2007.01.008)

Cooke JH, Patterson M, Patel SR, Smith KL, Ghatei MA, Bloom SR \& Murphy KG 2009 Peripheral and central administration of xenin and neurotensin suppress food intake in rodents. Obesity 17 1135-1143. (doi:10.1038/oby.2008.652)

Feurle GE, Heger M, Niebergall-Roth E, Teyssen S, Fried M, Eberle C, Singer MV \& Hamscher G 1997 Gastroenteropancreatic effects of xenin in the dog. Journal of Peptide Research 49 324-330. (doi:10.1111/ j.1399-3011.1997.tb01132.x)

Flatt PR \& Bailey CJ 1981 Abnormal plasma glucose and insulin responses in heterozygous lean (ob/+) mice. Diabetologia 20 573-577. (doi:10.1007/BF00252768)
Gault VA, Parker JC, Harriott P, Flatt PR \& O'Harte FP 2002 Evidence that the major degradation product of glucose-dependent insulinotropic polypeptide, GIP(3-42), is a GIP receptor antagonist in vivo. Journal of Endocrinology 175 525-533. (doi:10.1677/joe.0.1750525)

Hamscher G, Meyer HE \& Feurle GE 1996 Identification of proxenin as a precursor of the peptide xenin with sequence homology to yeast and mammalian coat protein $\alpha$. Peptides 17 889-893. (doi:10.1016/ 0196-9781(96)00150-7)

Irwin N, Frizelle P, Montgomery IA, Moffett RC, O'Harte FP \& Flatt PR 2012 Beneficial effects of the novel cholecystokinin agonist (pGlu-Gln)CCK-8 in mouse models of obesity/diabetes. Diabetologia 55 2747-2758. (doi:10.1007/s00125-012-2654-6)

Kim ER \& Mizuno TM 2010 Xenin delays gastric emptying rate and activates the brainstem in mice. Neuroscience Letters 481 59-63. (doi:10.1016/j.neulet.2010.06.055)

Leckstrom A, Kim ER, Wong D \& Mizuno TM 2009 Xenin, a gastrointestinal peptide, regulates feeding independent of the melanocortin signaling pathway. Diabetes 58 87-94. (doi:10.2337/db08-0260)

Martin CM, Gault VA, McClean S, Flatt PR \& Irwin N 2012 Degradation, insulin secretion, glucose-lowering and GIP additive actions of a palmitate-derivatised analogue of xenin-25. Biochemical Pharmacology 84 312-319. (doi:10.1016/j.bcp.2012.04.015)

Nauck MA, Heimesaat MM, Orskov C, Holst JJ, Ebert R \& Creutzfeldt W 1993 Preserved incretin activity of glucagon-like peptide 1 [7-36 amide] but not of synthetic human gastric inhibitory polypeptide in patients with type-2 diabetes mellitus. Journal of Clinical Investigation 91 301-307. (doi:10.1172/JCI116186)

Porter DW, Irwin N, Flatt PR, Hölscher C \& Gault VA 2011 Prolonged GIP receptor activation improves cognitive function, hippocampal synaptic plasticity and glucose homeostasis in high-fat fed mice. European Journal of Pharmacology 650 688-693. (doi:10.1016/j.ejphar. 2010.10.059)

Silvestre RA, Rodríguez-Gallardo J, Egido EM, Hernández R \& Marco J 2003 Stimulatory effect of xenin-8 on insulin and glucagon secretion in the perfused rat pancreas. Regulatory Peptides 115 25-29. (doi:10.1016/ S0167-0115(03)00147-2)

Taylor AI, Irwin N, McKillop AM, Patterson S, Flatt PR \& Gault VA 2010 Evaluation of the degradation and metabolic effects of the gut peptide xenin on insulin secretion, glycaemic control and satiety. Journal of Endocrinology 207 87-93. (doi:10.1677/JOE-10-0085)

Wice BM, Wang S, Crimmins DL, Diggs-Andrews KA, Althage MC, Ford EL, Tran H, Ohlendorf M, Griest TA, Wang Q et al. 2010 Xenin-25 potentiates glucose-dependent insulinotropic polypeptide action via a novel cholinergic relay mechanism. Journal of Biological Chemistry $\mathbf{2 8 5}$ 19842-19853. (doi:10.1074/jbc.M110.129304)

Received in final form 6 February 2014

Accepted 11 February 2014

Accepted Preprint published online 11 February 2014 (c) 2014 Society for Endocrinology Printed in Great Britain
Published by Bioscientifica Ltd 